\title{
The influence and countermeasures of digital economy on cultivating new driving force of high-quality economic development in Henan Province under the background of "double circulation"
}

\author{
Guo $\mathrm{Yu}^{1}$ (D) Xiaobo Zhou ${ }^{2}$
}

Accepted: 29 September 2021

(c) The Author(s), under exclusive licence to Springer Science+Business Media, LLC, part of Springer Nature 2021

\begin{abstract}
This article focuses on the impact of the digital economy on cultivating new driving force of high-quality economic development in Henan Province and the countermeasures under the background of the "double circulation". Through the research on the status quo of Henan Province's digital economy and high-quality economic development, it is concluded that since the reform and opening up, Henan Province has achieved rapid and steady development at the macroeconomic level. Since the reform and opening up, the output value of the three main industries in Henan Province has continued to grow and the industrial structure has continuously optimized. However, in the domestic horizontal comparison, the economic development of Henan Province has not yet formed a prominent advantage. Henan Province still needs to further optimize the economic development structure and promote high-quality economic development. Through the theoretical and empirical analysis of the digital economy's high-quality economic development in Henan Province under the background of the "double circulation", this project found that the development of the digital economy promotes the cultivation of new driving force of high-quality economic development in Henan Province under the background of the "double circulation". Henan Province needs to make full use of the development opportunities of the digital economy under the background of the "double circulation", and adopts a variety of comprehensive measures to take advantage of the situation to promote the high-quality development of the province's economy. The research of this project believes that under the background of "double circulation", Henan Province uses the digital economy to cultivate New driving force for high-quality economic development. Although certain results have achieved, some problems have exposed, mainly including the lagging foundation of using the digital economy to cultivate high-quality economic development. Failed to make full use of the digital economy to cultivate leading companies that promote high-quality economic development, the government has not fully adapted to the digital economy's demand for cultivating new driving force of high-quality economic development, and companies lack the talents to use the digital economy to promote their own
\end{abstract}

Guo Yu

gyu@zua.edu.cn

1 School of Economics, Zhengzhou University of Aeronautics, Zhengzhou, China

2 School of Finance and Economics, Henan Polytechnic University, Jiaozuo, China 
innovation and high-quality development. Further in-depth exploration found that the factors for the above problems mainly include not deeply the dual nature of production and consumption of digital infrastructure construction under the background of "double circulation", but ignoring the "pull the ox by the nose (grasp the key link)" status of leading enterprises in the cultivation of new driving force of high-quality economic development. The enthusiasm for the transformation of government functions and the adjustment of organizational structure is insufficient, and there are obstacles, and the introduction and training system of high-quality professionals in the field of digital economy is lacking. Through the mechanism analysis of the digital economy on the high-quality economic development of Henan Province under the background of the "double circulation", the analysis of development issues and causes combined with relevant literature analysis and field investigations. The project puts forward the use of digital in Henan Province Countermeasures for the economy to cultivate new driving force of high-quality economic development. Henan Province's digital infrastructure construction builds a solid foundation for high-quality economic development. The consumption upgrades as the engine used to cultivate a group of leading companies at the high end of the industrial value chain, improves the government support system, builds a support system for high-quality economic development in Henan Province, and strengthens the digital economy of enterprises by the use of professional talent team building.

Keywords Double circulation · Digital economy $\cdot$ High-quality development $\cdot$ New driving force $\cdot$ Henan Province

\section{Introduction}

2020 is an extraordinary year for both China and the world. The new crown pneumonia epidemic is raging around the world, the US trade suppression with China is rampant, and the social development in Central Europe and West Asia is turbulent. In this context, the global economic development is facing greater uncertainty, and China's export-oriented economic development pressure is increasing. In the face of the above-mentioned development status, the Standing Committee of the Political Bureau of the Communist Party of China, on May 14, 2020, made a forward-looking and timely proposal (Su \& Xia, 2020). Economic globalization, as a result of the rising cross-border commerce in goods and services, the movement of international money and the quick, broad spread of technology, refers to the increasing interdependency in global economies. The expert oriented growth strategy is one, in which country need economic development from the beginning of an international trade. An import substitution is the opposite function of export-led growth strategy. A trading country constitutes a major percentage of the economy in international commerce. Smaller countries tend to rely more on commerce than larger countries. A new plan for China's economic development in a complex environment is to promote the implementation of the "new development pattern of mutual promotion of domestic and international double circulation" (hereinafter referred to as "double circulation"). At the Third Session of the 13th National Committee of the Chinese People's Political Consultative Conference, General Secretary Xi Jinping proposed that meeting domestic demand would be the foundation for China's economic development in the future (Sheng, 2020). In the "double circulation" system, domestic recycling will become the focus. The pandemic has encouraged people's need for a better living and made increased demands on property items and services. China's macroeconomics and immobilizing industry have been confronted with numerous uncertainties and problems 
by the new coronavirus pneumonia and have enormous potential. It is necessary to promote the construction of a domestic demand system and technology. In particular, it is necessary to accelerate the development of strategic emerging industries such as the digital economy to form more new growth points and growth poles (Jia et al., 2020). At the same time, the "double circulation" system will help to further open up all links from production to consumption, and continue to enhance the vitality and innovation of China's economic development.

Looking at the global digital economy, it has become the main direction of the development of all countries, especially in Western Europe, North America, and Japan. The development of the digital economy has become one of the main directions for the government to promote economic upgrading. General Secretary Xi Jinping has repeatedly proposed to promote the development of China's digital economy on many occasions, and the development of the digital economy in the context of the "double circulation" has ushered in historical opportunities (Wang et al., 2020). The major benefits digital economy is digitization and tracking, connection and personalised data. In Digitized and tracking, the signals generated by the analog objects is measured, analyzed and tracked to make clear decision making. Then, the connection links the suppliers, workers, and assets by wireless communication with improved and efficient information. With the advantages of the times and the support of the central policy, Henan Province, as a major province in central China with abundant digital resources, attaches great importance to the development of the digital economy. On July 2, 2019, Henan Province issued the "Key Points of Henan Province's Digital Economy Work in 2019". It has clearly proposed to strengthen the construction of digital infrastructure, and the digital economy has become an important driving force for high-quality economic development (Han \& Dong, 2020). At the same time, the provincial capital city of Zhengzhou also issued the "Notice of Zhengzhou City's Implementation Plan for Accelerating the Development of Digital Economy for 2020-2022" on January 22, 2020, proposing to further promote the development of the city's digital productivity and promote the transformation of economic development in the direction of digital economy (Yang, 2020). As an inland province in the conventional economic development model, Henan Province is difficult to form a comprehensive comparative advantage over coastal provinces. The development of a digital economy to promote the high-quality development of the province's economy is an opportunity for Henan Province to catch up and "Corner overtaking" (Ming, 2020). Higher economic growth leads to increased business profitability, resulting in increased R\&D expenditure. Sustainable economic growth builds trust and supports risk-taking and innovation in companies. The optimization is the process of regulating the particular set of parameters without losing any constraints. Maximizing and minimizing the cost and efficiency of the product is the major goal of optimization. It is one of the major tool used in the industrial decision making process (Raza et al., 2020). However, under the background of "double circulation", how to use the digital economy to cultivate New driving force for high-quality economic development in Henan Province is a new subject. There are currently few reference materials and practical experience for this subject, but it is currently necessary (Shi, 2020). Therefore, in the context of the "double circulation", this article combines the direction of the central government's policy to deeply study the internal mechanism of the digital economy to promote high-quality economic development, explore the implementation strategies and operational paths of the digital economy to drive high-quality economic development, and promote the industrial structure of Henan Province. An economic development is the serious component that drives the economic growth of the country. It also used to improve high wage jobs and enables the improved quality of life of the people. If an economic development is processed effectively means the investment of the job enhanced with wealth of the country. The traditional factordriven industry is transforming into a digital-driven innovation industry (Ren, 2020). In the 
end, it provides a reference for decision-makers to formulate a more scientific and reasonable economic development policy. Factor-driven economies are the least developed, but the efficiency-driven economies are becoming more competitive, and inventive economies are the most advanced, thanks to more efficient production processes and higher product quality.

\section{Research objective and objects}

\subsection{Research objective}

By analyzing the impact of digital economy on the cultivation of new drivers of high-quality economic development in Henan Province under the background of "dual cycles", this article constructs an impact mechanism and analyzes the existence of new drivers of digital economy for cultivating high-quality economic development of Henan Province under the background of "dual cycles" The digital economy is an economy, the process based on digital computing technologies to increase the business through markets with the help of World Wide Web and internet. It is also known as web economy, internet economy or new economy. The problem and cause. On this basis, this article proposes optimization and improvement measures, and finally achieves the goal of promoting the high-quality economic development of Henan Province.

\subsection{Research objects}

The research object of this paper is the new driving force of high-quality economic development in Henan Province under the background of "double circulation".

\section{Research methods}

This topic focuses on the use of digital economy in Henan Province to cultivate new driving force of high-quality economic development under the background of "double circulation". The optimization is the process of regulating the particular set of parameters without losing any constraints. Maximizing and minimizing the cost and efficiency of the product is the major goal of optimization. It is one of the major tool used in the industrial decision making process (Ding, 2020). With the help of literature analysis method, based on fully reading the existing research results at home and abroad, through field investigation method and model quantitative analysis method, the application of the "double circulation" background demonstrates the mechanism for Henan Province to use the digital economy to cultivate New driving force for high-quality economic development (Zhang et al., 2019). Field investigation is the study of human cultural traces at any location via surveying, sampling, excavating, or removing surface or subsurface material, or travelling to a site with certain goal. Quantitative model is nothing but the compressed representation, in which single difference or differential equation is used to explain the system performance either for initial state or for larger set of input functions. At the same time, with the help of case analysis method and comparative analysis method, the problems of Henan Province using the digital economy to cultivate new driving force of high-quality economic development under the background of the "double circulation" were discussed, and solutions to the problems were designed to strengthen the "double circulation" (Xiao \& Zhang, 2019). The case analysis method involves in the study of reality of business situations, it explains the detailed presentation of the organization 
marketing with its strategic decisions. It is also used to improve the student problem solving ability by examining the modern issues of real-life context and the comparative analysis is the method, which involves in the study of systematic way of configuration cases. The comparative analysis method is widely classified into two different types such as qualitative and quantitative comparative analysis. In which, the qualitative analysis using case study of the research method to analyze the comparative results of the system (Jing \& Sun, 2019). Under the background of "circulation", Henan Province is able to use the digital economy to cultivate new driving force of high-quality economic development. The consumer spending is considered as the major driving force of economy, because the user use or buy something produce the demand of the products. So, automatically the job growth in particular area is increased. Meanwhile, Human capital is determined by calculating the number of employees in the year by their average years of schooling (Balusamy et al., 2019).

\section{Research results}

\subsection{The overall status quo of economic development in Henan Province}

\subsubsection{The economic development status of Henan Province since the reform and opening up}

Henan Province has been an important region for China's economic development since ancient times. Since 1978, under the support of national policies, Henan Province has achieved rapid economic development. An economic growth depends on the production of services and goods in a particular economy. Increase in technology, human capital, labor force and capital goods also leads to economic growth. Major indicators of economic growth depends on the measurement of GNP, GNP per capita, GDP per capita and GDP. So, the country's income gap between richest and poorest people depends on the inequality of the wealth (Cao, 2018). The growth of regional GDP and per capita GDP is particularly prominent. Table 1 shows the total GDP and per capita GDP of Henan Province from 1978 to 2020. From Table 1 , we can see the following information. (1) From the table data, it can be seen that the total GDP of Henan Province has maintained a continuous growth trend since 1978, from 16.292 billion yuan to 54,997.07 Billion yuan, a cumulative growth of 5483.415 billion yuan, and an average annual growth rate of $782.72 \%$ in 43 years. (2) Henan's per capita GDP has also been growing rapidly since 1978, increasing from 232 yuan in 1978 to 56,388 yuan in 2019, The cumulative increase was 56,156 yuan, and the average annual growth rate in 42 years reached $576.31 \%$ (Shen \& Zhao, 2020). Although slightly lower than the average annual growth rate of Henan Province's GDP, it also maintained a relatively high growth rate. From the above data, it can be seen that since the reform and opening up, Henan Province has achieved rapid and steady development at the macroeconomic level (Zhu \& Wang, 2020).

\subsubsection{The status of Henan's economy in the national economy}

Since the reform and opening up, especially since 2000, China's economy has achieved rapid and steady development. Both the overall economy of China and the regional economy of Henan Province have both improved in quantity and quality (Liu, 2019). Figure 1 shows China's GDP data from 2000 to 2020 and the proportion of Henan's GDP in China's total GDP. Figure 1 shows that both China and Henan's GDP have continued to rise during the 
Table 1 GDP and GDP per capita of Henan Province from 1978 to 2020. Source: "Henan Statistical Yearbook" of each year

\begin{tabular}{|c|c|c|c|c|c|}
\hline Time & $\begin{array}{l}\text { GDP ( } 100 \text { million } \\
\text { yuan) }\end{array}$ & $\begin{array}{l}\text { per capita GDP } \\
\text { (yuan) }\end{array}$ & Time & GDP (100 million yuan) & $\begin{array}{l}\text { per capita GDP } \\
\text { (yuan) }\end{array}$ \\
\hline 1978 & 162.92 & 232 & 2000 & 5052.99 & 5450 \\
\hline 1979 & 190.09 & 267 & 2001 & 5533.01 & 5959 \\
\hline 1980 & 229.16 & 317 & 2002 & 6035.48 & 6487 \\
\hline 1981 & 249.69 & 340 & 2003 & 6942.41 & 7376 \\
\hline 1982 & 263.30 & 353 & 2004 & 8411.19 & 9047 \\
\hline 1983 & 327.95 & 433 & 2005 & $10,243.47$ & 10,978 \\
\hline 1984 & 370.04 & 482 & 2006 & $11,977.87$ & 12,761 \\
\hline 1985 & 451.74 & 580 & 2007 & $14,824.49$ & 15,811 \\
\hline 1986 & 502.91 & 635 & 2008 & $17,735.93$ & 18,879 \\
\hline 1987 & 609.60 & 756 & 2009 & $19,181.00$ & 20,280 \\
\hline 1988 & 749.09 & 910 & 2010 & $22,655.02$ & 23,984 \\
\hline 1989 & 850.71 & 1012 & 2011 & $26,318.68$ & 28,009 \\
\hline 1990 & 934.65 & 1091 & 2012 & $28,961.92$ & 30,820 \\
\hline 1991 & 1045.73 & 1201 & 2013 & $31,632.50$ & 33,618 \\
\hline 1992 & 1279.75 & 1452 & 2014 & $34,574.76$ & 36,686 \\
\hline 1993 & 1660.18 & 1865 & 2015 & $37,084.10$ & 39,209 \\
\hline 1994 & 2216.83 & 2467 & 2016 & $40,249.34$ & 42,341 \\
\hline 1995 & 2988.37 & 3297 & 2017 & $44,824.92$ & 46,959 \\
\hline 1996 & 3634.69 & 3978 & 2018 & $49,935.90$ & 52,114 \\
\hline 1997 & 4041.09 & 4389 & 2019 & $54,259.20$ & 56,388 \\
\hline 1998 & 4308.24 & 4643 & 2020 & $54,997.07$ & - \\
\hline 1999 & 4517.94 & 4832 & & & \\
\hline
\end{tabular}

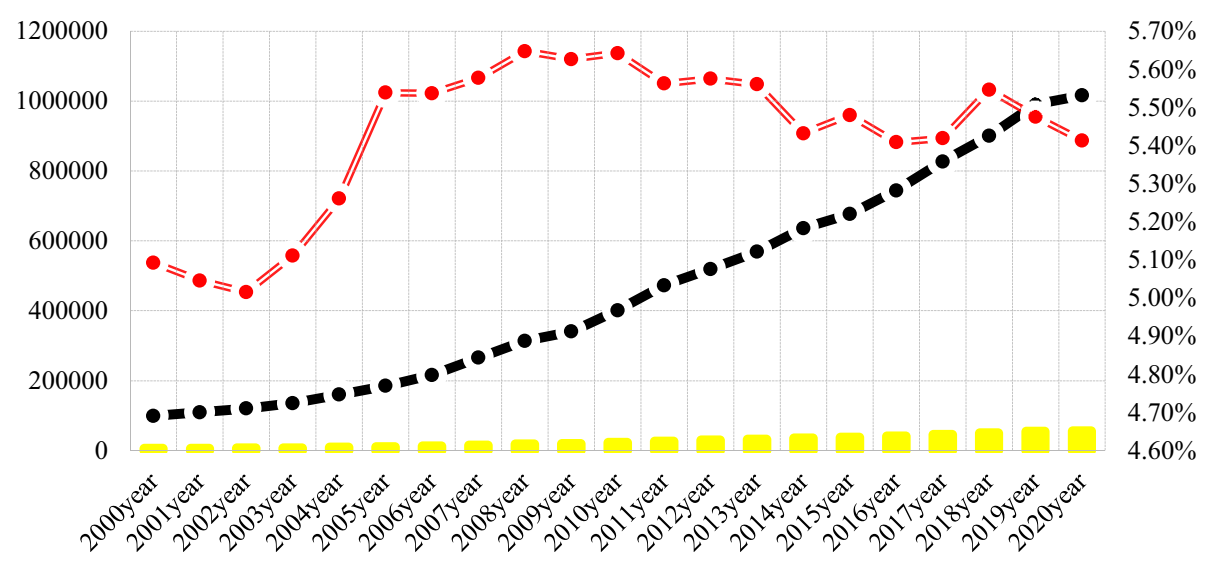

Henan's GDP $=$ China's GDP $=\cdot=$ Proportion of Henan's GDP in national GDP

Fig. 1 Major economic development data of China and Henan from 2000 to 2020. Data source: "China Statistical Yearbook" and "Henan Statistical Yearbook" of each year 
statistical period, especially in 2020. The economy has also maintained growth. During the same period, the proportion of Henan's total economy in the country fluctuated between 5.02 and $5.65 \%$ (Fan \& Xu, 2020). Among them, the lowest proportion in the country in 2002 was $5.02 \%$, and the highest proportion in the country in 2008 was $5.65 \%$. However, after entering 2019, the proportion of Henan Province's total economy in the whole country has a downward trend. Therefore, although from a vertical comparison, Henan Province has achieved rapid economic development ( $\mathrm{Li}$ et al., 2020). However, in terms of horizontal comparison, the economic development of Henan Province has not yet formed a prominent advantage. Henan Province needs to further optimize its economic development structure and promote high-quality economic development.

\subsubsection{Evolution of the industrial structure of Henan Province}

In the process of economic development in Henan Province, the development of the three main industries reflects the structure and quality of its economic development, which can also indicate to a certain extent the achievements or deficiencies of Henan Province's highquality economic development (Sheng, 2020). Table 2 statistics the output value data of the three main industries in Henan Province from 1978 to 2020. From the table, we can see the following relationship. Henan is the province located in the central china yellow river valley, this is the place where the Chinese organization is invented. Henan province having three main capital borders including home to Baima Si, Luoyang and capital during multiple dynasties. It is an area of about 167, 000 Sq.km with the population of about 100 million (Alvarez \& Crespo, 2013).

1. Since 1978, the output value of the primary, secondary, and tertiary industries in Henan Province has increased from 6.486 billion yuan to 535.374 billion yuan, 6.945 billion yuan to 2.287533 billion yuan, 2.861 billion yuan to 2.676801 billion yuan, respectively. The cumulative growth rate is $8154.30 \%, 32,837.84 \%$, and $93,461.73 \%$.

2. Analysis from the comparison of the growth rate of the three main industries in Henan Province shows that the cumulative growth rate of the output value of the tertiary industry is the fastest, far exceeding that of the secondary industry and the primary industry, and the growth rate is 11.46 times that of the primary industry. In the process of economic development in Henan Province, the service industry has developed rapidly, and the economic development structure has further optimized.

3. From the absolute value comparison of the three main industries in Henan Province, the output value of the primary industry in 1978 was higher than that of the tertiary industry, although it was lower than the output value of the secondary industry, but the gap between the two was relatively small(Guo \& Lian, 2020; Wen et al., 2020; Zhang, 2019). In 1992, the output value of the tertiary industry exceeded that of the first industry for the first time. Afterwards, the gap between the two industries quickly widened. At this time, the gap between the output value of the primary industry and the output value of the secondary industry further widened. In 2018, the output value of the tertiary industry exceeded the output value of the secondary industry for the first time. The gap between them has gradually widened (Grigorescu et al., 2021; Sturiale \& Scuderi, 2016). As of 2020, the output value of the tertiary industry has become the largest industry in Henan Province, and the output value of the tertiary industry is 1.102 times and 5.613 times that of the secondary industry and the primary industry respectively (Grigorescu et al., 2021; Sturiale \& Scuderi, 2016). 
Table 2 Development data of the three main industries in Henan Province from 1978 to 2020 (100 million yuan). Source: "Henan Statistical Yearbook" of each year

\begin{tabular}{rrrrrrrr}
\hline Time & $\begin{array}{l}\text { Primary } \\
\text { industry } \\
\text { (GDP) }\end{array}$ & $\begin{array}{l}\text { Secondary } \\
\text { industry } \\
\text { (GDP) }\end{array}$ & $\begin{array}{l}\text { Tertiary } \\
\text { industry } \\
\text { (GDP) }\end{array}$ & Time & $\begin{array}{l}\text { Primary } \\
\text { industry } \\
\text { (GDP) }\end{array}$ & $\begin{array}{l}\text { Secondary } \\
\text { industry } \\
\text { (GDP) }\end{array}$ & $\begin{array}{l}\text { Tertiary } \\
\text { industry } \\
\text { (GDP) }\end{array}$ \\
\hline 1978 & 64.86 & 69.45 & 28.61 & 2000 & 1124.93 & 2282.48 & 1645.59 \\
1979 & 77.30 & 80.52 & 32.27 & 2001 & 1195.39 & 2497.71 & 1839.91 \\
1980 & 93.23 & 94.44 & 41.49 & 2002 & 1207.11 & 2881.60 & 1946.77 \\
1981 & 106.04 & 95.79 & 47.86 & 2003 & 1198.70 & 3348.63 & 2395.08 \\
1982 & 108.18 & 102.76 & 52.36 & 2004 & 1647.57 & 4080.74 & 2682.88 \\
1983 & 143.49 & 116.36 & 68.10 & 2005 & 1844.04 & 5202.27 & 3197.16 \\
1984 & 155.28 & 136.29 & 78.47 & 2006 & 1869.82 & 6316.19 & 3791.86 \\
1985 & 173.43 & 170.07 & 108.24 & 2007 & 2156.69 & 7904.01 & 4763.80 \\
1986 & 179.02 & 202.15 & 121.74 & 2008 & 2575.81 & 9713.40 & 5446.72 \\
1987 & 220.22 & 230.25 & 159.13 & 2009 & 2665.66 & $10,324.57$ & 6190.77 \\
1988 & 240.72 & 299.83 & 208.54 & 2010 & 3127.14 & $12,173.51$ & 7354.38 \\
1989 & 289.95 & 317.13 & 243.63 & 2011 & 3349.25 & $14,021.59$ & 8947.84 \\
1990 & 325.77 & 331.85 & 277.03 & 2012 & 3577.15 & $15,042.55$ & $10,342.21$ \\
1991 & 334.61 & 388.09 & 323.03 & 2013 & 3827.20 & $15,995.37$ & $11,809.92$ \\
1992 & 342.75 & 542.40 & 394.60 & 2014 & 3988.22 & $17,139.61$ & $13,446.93$ \\
1993 & 397.50 & 760.24 & 502.44 & 2015 & 4015.56 & $17,947.86$ & $15,120.68$ \\
1994 & 529.43 & 1053.35 & 634.05 & 2016 & 4063.64 & $18,986.89$ & $17,198.81$ \\
1995 & 738.91 & 1387.65 & 861.81 & 2017 & 4139.29 & $20,940.33$ & $19,745.30$ \\
1996 & 908.05 & 1668.88 & 1057.75 & 2018 & 4311.12 & $22,038.56$ & $23,586.21$ \\
1997 & 976.73 & 1851.70 & 1212.66 & 2019 & 4635.40 & $23,605.79$ & $26,018.01$ \\
1998 & 1037.58 & 1927.95 & 1342.70 & 2020 & 5353.74 & $22,875.33$ & $26,768.01$ \\
1999 & 1087.70 & 1970.98 & 1459.26 & & & & \\
\hline & & & & & & &
\end{tabular}

In summary, since the reform and opening up, Henan's economy has achieved sustained and rapid development as a whole. The output value of the three main industries has continued to grow and the industrial structure has continuously optimized. The primary industry, secondary industry and tertiary industry are combined to grow the industrial structure and economic growth of the country. At present, the three-industry structure is 9.7: 41.6: 48.7 .

\subsection{Empirical analysis of the impact of digital economy on high-quality economic development}

\subsubsection{Variable selection and data sources}

According to the theoretical analysis above, the digital economy can promote the development of regional economy. Theoretical analysis is mainly used to examine the issues in decision process methods to determine the individualities of the problem description with initial data impact on obtained results. The influence of digital economy on regional economic development puts under the background of "double circulation", we can draw two key points for digital economy to promote the high-quality development of regional economy. 
Key point 1: In the process of regional economic development, digital information technology must play a fully empowering role to ensure that digital information technology can have better integrated into economic development; Digital information technology is the technology which fully involves in the uses and examining of internet, spreadsheet, and management of personal information like email, databases, document manipulation, application presentation and word processing with the help of software programs.

Key point 2: Under the background of "double circulation", the high-quality development of regional economy relies on digital consumption motivation and influencing factors, tapping market consumption potential, and identifying the development trend of digital economy.

Based on the above analysis, this article takes Henan Province as the object and selects 10 aspects (indicators) for empirical analysis under the background of "double circulation". The specific connotations of each indicator are as follows.

1. Resident disposable income (KZPSR). In the context of the "double circulation", the residents' disposable income will affect the residents' consumption capacity, including the consumption capacity of digital products, thereby further affecting the role of consumption in promoting high-quality economic development.

2. Resident income gap (CX). The income gap of residents affects the difference in the consumption ability of residents for products. If the income gap of residents is larger, the imbalance of consumption will be higher, and it will affect the role of consumption in promoting high-quality economic development.

3. Digital Product Consumer Price Index (DCPI). Under the background of "double circulation", the selling price of digital products on the market will affect the production enthusiasm of all parties and the consumption of consumers, thereby having an impact on the high-quality economic development. The DPI is the abbreviated term of Digital price index, then the differences between DPI and CPI is based on its theoretical explanation. It mainly occurs during the demand of the product in the market.

4. Commodity price index (RPI). In the context of the "double circulation", the digital economy will empower the production activities of a variety of commodities, which will affect the price index of different commodities. Consumer price index (CPI) is mainly used to measure the changes in general level of retail price over time for selected goods and services. It compares the price changes to determine the total cost of the fixed basket. The changes in the general level of retail price widely affects the consumer welfare and income. The change of this indicator will further affect the consumption ability of consumers. The implementation of "has an impact.

5. Unemployment rate (SYL). The unemployment rate reflects the employment status and income status of residents. The level of unemployment rate has a direct impact on the realization of the "double circulation". At the same time, it will also affect people's consumption of digital products and the high-quality development of the regional economy.

6. The proportion of labor force (LDL). The proportion of the labor force reflects the proportion of the labor force in Henan Province in the total population under the background of the "double circulation", and is an important factor influencing regional production and consumption in the era of digital economy.

7. Social dependency ratio (FY). The social dependency ratio reflects the proportion of the population that the society needs to support, and is an important indicator to measure the ability of the residents of Henan Province to consume digital economy products under the background of "double circulation". 
8. The number of netizens (WM). The number of netizens reflects the number of Internet residents in Henan Province, and is an important evaluation factor for residents' exposure to digital products and driving the development of digital product sales under the background of "double circulation".

9. Intelligent terminal retention rate (BYL). In the context of the "double circulation", the retention rate of smart terminals can reflect the convenience and scale of residents' consumption of digital economy products, and it can also indirectly reflect the impact on the high-quality development of the regional economy from the level of digital products.

10. The quality of economic development in Henan Province (Y). Taking Y as the dependent variable reflects the impact of the digital economy on the high-quality economic development of Henan Province through the role of a variety of specific factors in the context of "double circulation".

After completing the selection of the above variables, this topic collects the panel data of the above variables from 2006 to 2020 . The data sources are as follows: the "Henan Statistical Yearbook" and "China Civil Affairs Statistical Yearbook" of each year, as well as the Henan Provincial Department of Civil Affairs, Henan The internal statistics of the Provincial Department of Science and Technology and other government agencies.

\subsubsection{Factor analysis}

(1) Standardization of evaluation factors

Since the 9 independent variable evaluation factors selected in this project have both quantitative and qualitative types, the selected evaluation factors have differences in attributes, and it is difficult to conduct comprehensive analysis and comparison in dimensional or quantitative level dimensions. An objective measurements or the numerical analysis of the data collected through surveys, questionnaires, manipulating pre-existing statistical data and polling by using computational techniques is called quantitative analysis. The quantitative analysis deals with the study of statistics and numbers, but the qualitative research deals with the study of meanings and words. Then, the quantitative analysis measures the test hypothesis and variables. Likewise, the qualitative analysis method describes the experience and concept of variable in detailed manner (Nguyen et al., 2017). To this end, this article first standardizes the 9 independent variable evaluation factors, so as to eliminate the adverse effects caused by attribute differences. The formula (1) used for standardization:

$$
B X_{i}=\frac{X_{i}-E\left(X_{i}\right)}{\sqrt{\operatorname{Var}\left(X_{i}\right)}}
$$

In formula (1), $B X_{i}$ represents the standard value obtained after the variable $X_{i}$ is standardized. $E\left(X_{i}\right)$ is the mean value of the variable $X_{i}$ after statistics. $\operatorname{Var}\left(X_{i}\right)$ is the value of the variable $X_{i}$ after calculating the variance. Through formula (1) to standardize all variables, the results shown in Table 3 have obtained.

(2) Index adaptability test

When judging whether certain indicators are suitable for factor analysis models, the KMO test and the Bartlett sphere test are used in academia. The Bartlett's test method is the method, which test the equal variance of the sample values. An equal variance present in sample value is generally known as homogeneity variance. Analysis of variance adopt the variance in the sample are equal across groups in statistical analysis test (AbdelBasset et al., 2018). Among them, the value of the KMO test is between 0 and 1 . In 
the multivariate statistical analysis, the test value is larger; the correlation of the tablesister factors is stronger, which is the more suitable for analysis. KMO test is the test method, which mainly used to evaluate the sampling sustainability of the data to process in factor analysis. The factor analysis is used to confirm that the variables are measured with particular concept. The KMO test calculation is shown in formula (2).

$$
K M O=\frac{\sum \sum_{i \neq j} r_{i j}^{2}}{\sum \sum_{i \neq j} r_{i j}^{2}+\sum \sum_{i \neq j} p_{i j}^{2}}
$$

In formula (2), $r_{i j}$ reflects the correlation between different variables $X_{i}$ and $X_{j}$, which is the correlation between different variables $X_{i}$ and $X_{j}$. Kaise and other scholars proposed that factor analysis could have carried out when the KMO test value is not less than 0.5 , otherwise it means that the selected factor is not suitable for factor analysis and needs to be re-adjusted. The results shown in Table 4 are obtained through inspection. According to the test result, the KMO test value is significantly greater than 0.5 and the Sig. value is significantly less than 0.5 . Therefore, the selected index can be used for factor analysis. Kaiser-Meyer-Olkin (KMO) test evaluates the capability of the sample data to check whether the data is appropriate for dataset of factor analysis process. But the Bartlett' test of sphericity determines the null hypothesis of the variables with the help of uncorrelated population correlation matrix.

(3) Calculation of load matrix

In the factor analysis method, the implementation of load matrix calculation is the key link, but the difference of the specific calculation method will affect the calculation result. The factor extraction method is used to reduce the squared variations among reproduced and overlapped correlation matrices. But the weight of the correlation are opposite to the uniqueness, if the variable with high uniqueness mean the weight of the correlation having

Table 3 Standardization results of evaluation indicators. Source: Calculated and summarized by the author

\begin{tabular}{lllll}
\hline Independent variable & Min & Max & AVG & SD \\
\hline KZPSR & $10,283.4$ & $46,483.1$ & $24,768.8$ & $10,576.4$ \\
CX & 2.1 & 3.4 & 2.9 & 0.3 \\
DCPI & 464.0 & 669.8 & 570.2 & 66.2 \\
RPI & 359.1 & 471.5 & 421.9 & 36.1 \\
SYL & 3.2 & 4.4 & 4.0 & 0.2 \\
LDL & 46.3 & 79.4 & 53.3 & 57.6 \\
FY & 11.8 & 19.3 & 14.5 & 3.1 \\
WM & $31,118,418$ & $79,587,521$ & $53,609,130$ & $46,372,126$ \\
BYL & 40.1 & 83.4 & 66.8 & 50.7 \\
\hline
\end{tabular}

Table 4 Evaluation index test results. Source: Calculated and summarized by the author
KMO laboratory value

0.783

Bartlett sphericity test
357.32

35

0.000 
minimum uniqueness. The load matrix is a systematic approach, which is used to make the novel or optimistic program for evaluation process. The component-specific test acceleration factors and damaged models are based on this process of its statistics. In this topic, the extraction factor method is selected, as shown in Table 5. The common factor variance indicates that the extracted data from the variable can be expressed if the value is greater than 0.5. According to the calculation results in Table 5, the common factor variance extraction value of all data is greater than 0.5 .

The cumulative variance contribution rate is further calculated and the data shown in Table 6 and Fig. 2 are obtained. From this, it can be concluded that the variance percentage contribution of component 1 and component 2 is higher, which are $85.627 \%$ and $9.689 \%$ in sequence, and the proportion of component 1 and component 2 The cumulative value of the variance percentage is $95.316 \%$. At the same time, the gap between component 1 and component 2 is relatively large, and the change between component 2 and component 9 is relatively smooth. Therefore, for dimensionality reduction, the variance value of component 1 and component 2 is selected to replace the overall variance value.

Combining the above analysis, construct a rotating component matrix to clarify the evaluation factors of component 1 and component 2 , and then use the original variable to replace

Table 5 Common factor variance of evaluation index. Source: Calculated and summarized by the author

\begin{tabular}{lll}
\hline Standardized variate & Initial value & Extraction value \\
\hline B (KZPSR) & 1.000 & 0.992 \\
B (CX) & 1.000 & 0.869 \\
B (DCPI) & 1.000 & 0.905 \\
B (RPI) & 1.000 & 0.959 \\
B (SYL) & 1.000 & 0.556 \\
B (LDL) & 1.000 & 0.864 \\
B (FY) & 1.000 & 0.813 \\
B (WM) & 1.000 & 0.985 \\
B (BYL) & 1.000 & 0.876 \\
\hline
\end{tabular}

Table 6 Cumulative variance contribution rate. Source: Calculated and summarized by the author

\begin{tabular}{lccc}
\hline Ingredients & Total & Percentage of variance $(\%)$ & Cumulative percentage \\
\hline 1 & 7.500 & 85.627 & 85.627 \\
2 & 0.916 & 9.689 & 95.316 \\
3 & 0.305 & 2.276 & 97.592 \\
4 & 0.155 & 1.803 & 99.395 \\
5 & 0.017 & 0.204 & 99.599 \\
6 & 0.013 & 0.182 & 99.781 \\
7 & 0.003 & 0.157 & 99.938 \\
8 & 0.002 & 0.061 & 99.999 \\
9 & 0.000 & 0.001 & 100.000 \\
\hline
\end{tabular}




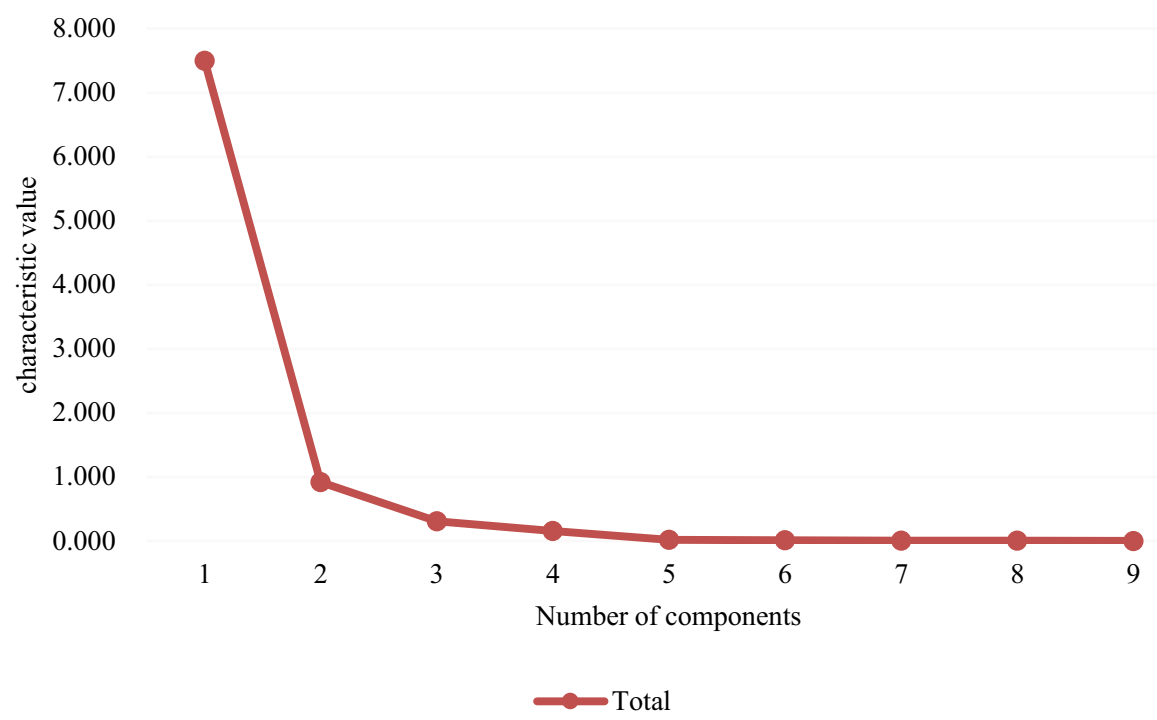

Fig. 2 Factor analysis debris diagram. Source: Calculated and summarized by the author

Table 7 Component score coefficient. Source: Calculated and summarized by the author

\begin{tabular}{lcc}
\hline Independent variable & Component 1 & Component 2 \\
\hline B (KZPSR) & 0.996 & 0.079 \\
B (CX) & -0.932 & -0.024 \\
B (DCPI) & 0.997 & -0.066 \\
B (RPI) & 0.979 & -0.171 \\
B (SYL) & -0.738 & -0.578 \\
B (LDL) & -0.694 & 0.670 \\
B (FY) & 0.964 & 0.251 \\
B (WM) & 0.992 & -0.103 \\
B (BYL) & 0.935 & 0.041 \\
\hline
\end{tabular}

the linear equation of the principal component factor to obtain the factor score function, as shown in Table 7.

According to the data shown in Table 7, the linear relationship between component 1 and component 2 can be obtained, as follows:

1. $F_{1}=0.996 \mathrm{~B}_{(\mathrm{KZPSR})}-0.932 \mathrm{~B}_{(\mathrm{CX})}+0.997 \mathrm{~B}_{(\mathrm{DCPI})}+0.979 \mathrm{~B}_{(\mathrm{RPI})}-0.738 \mathrm{~B}_{(\mathrm{SYL})}-$ $0.694 \mathrm{~B}_{(\mathrm{LDL})}+0.964 \mathrm{~B}_{(\mathrm{FY})}+0.992 \mathrm{~B}_{(\mathrm{WM})}+0.935 \mathrm{~B}_{(\mathrm{BYL})}$

2. $F_{2}=0.079 \mathrm{~B}_{(\mathrm{KZPSR})}-0.024 \mathrm{~B}_{(\mathrm{CX})}-0.066 \mathrm{~B}_{(\mathrm{DCPI})}-0.171 \mathrm{~B}_{(\mathrm{RPI})}-0.578 \mathrm{~B}_{(\mathrm{SYL})}+$ $0.670 \mathrm{~B}_{(\mathrm{LDL})}+0.251 \mathrm{~B}_{(\mathrm{FY})}-0.103 \mathrm{~B}_{(\mathrm{WM})}+0.041 \mathrm{~B}_{(\mathrm{BYL})}$.

\subsubsection{Regression analysis}

Regression analysis can show the degree of influence on the explained variable by changing the relationship between variables. The regression analysis the set of statistical method, it is mainly used for the determination of relationship between one or more dependent variable 
Table 8 Regression analysis results. Source: Calculated and summarized by the author

\begin{tabular}{llllll}
\hline Model & standard coefficient & \multicolumn{2}{l}{ Non-standard coefficient } & \multirow{2}{*}{ Sig } \\
\cline { 4 - 5 } & & Standard error & $b$ & \\
\hline (Constant) & - & 0.081 & -0.123 & -1.549 & 0.146 \\
$\mathrm{~F}_{1}$ & 0.951 & 0.012 & 0.124 & 11.654 & 0.000 \\
$\mathrm{~F}_{2}$ & 0.168 & 0.091 & 0.187 & 2.103 & 0.059 \\
\hline
\end{tabular}

with dependent variable. Then, the strength of the variable and modeling of the future relationship between the variables is utilized with the help of regression analysis. In the research of this subject, two explanatory variables, component 1 and component 2 , are used to explain the dependent variable Y. Perform regression analysis on the independent variable and the dependent variable, and get the results shown in Table 8. From the table, we can see:

Therefore, we can further obtain $\mathrm{B}_{(\mathrm{Y})}=0.124 \mathrm{~F}_{1}+0.187 \mathrm{~F}_{2}$. Then, multiply the coefficient vector of component 1 and component 2 and the principal component regression coefficient vector.

$$
\left[\begin{array}{cc}
0.996 & 0.079 \\
-0.932 & -0.024 \\
0.997 & -0.066 \\
0.979 & -0.171 \\
-0.738 & -0.578 \\
-0.694 & 0.670 \\
0.964 & 0.251 \\
0.992 & 0.103 \\
0.935 & 0.041
\end{array}\right] \times\left[\begin{array}{l}
0.124 \\
0.187
\end{array}\right]=\left[\begin{array}{c}
0.1383 \\
-0.1201 \\
0.1113 \\
0.0894 \\
-0.1996 \\
0.0392 \\
0.1665 \\
0.1037 \\
0.1236
\end{array}\right]
$$

From this, we can get $\mathrm{B}_{(\mathrm{Y})}=0.1383 \mathrm{~B}_{(\mathrm{KZPSR})}-0.1201 \mathrm{~B}_{(\mathrm{CX})}+0.1113 \mathrm{~B}_{(\mathrm{DCPI})}$ $+0.0894 \mathrm{~B}_{(\mathrm{RPI})}-0.1996 \mathrm{~B}_{(\mathrm{SYL})}+0.0392 \mathrm{~B}_{(\mathrm{LDL})}+0.1665 \mathrm{~B}_{(\mathrm{FY})}+0.1037 \mathrm{~B}_{(\mathrm{WM})}+$ $0.1236 \mathrm{~B}_{(\mathrm{BYL})}$.

According to the results of the regression analysis, in the context of the "double circulation", the digital economy is used to promote the high-quality economic development of Henan Province, except for the residents' income gap (CX) and unemployment rate (SYL), which cannot form a positive promotion effect. Residents are at their disposal. Income (KZPSR), Digital Product Consumer Price Index (DCPI), Commodity Price Index (RPI), Labor Force Ratio (LDL), Social Dependency Ratio (FY), Number of Internet Users (WM), Smart Terminal Ownership Rate (BYL) and other indicators. The commodity price index is the index, which defines the weighted average of particular commodity price based in their predicted future prices. Basically, it is designed to represent the assets class of broad commodity like energy and metal producing industries. The growth of $1 \%$ will drive the economy of Henan Province to rise by $0.1383 \%, 0.1113 \%, 0.0894 \%, 0.0392 \%, 0.1665 \%, 0.1037 \%$, $0.1236 \%$, respectively, in the context of the digital economy. Therefore, the development of the digital economy under the background of "double circulation" has a promoting effect on cultivating new driving force of high-quality economic development in Henan Province. Henan Province needs to make full use of the development opportunities of the digital economy under the background of "double circulation" and adopt a variety of comprehensive 
measures to take advantage of the momentum, which help to promote the high-quality development of the province's economy.

\section{Analysis and discussion}

\subsection{Under the background of "double circulation", Henan Province adopts the digital economy to cultivate new driving force of high-quality economic development.}

\subsubsection{The foundation for using the digital economy to cultivate high-quality economic development is lagging behind}

Under the background of "double circulation", Henan Province needs to focus on two key points of economic development: one is to improve the competitiveness of export products. The other is to improve the production and supply capabilities of domestic products. Whether it is to improve the competitiveness of export products or continuously improve the production and supply capabilities of domestic products, the current development environment cannot do without the empowerment of the digital economy. Without the empowerment of the digital economy, the development path of the traditional model will not be able to seize the strategic opportunity of the "double circulation" for Henan Province, which has a weak traditional industrial foundation and relatively weak regional competitiveness. Therefore, in order to achieve high-quality economic development in Henan Province under the background of the "double circulation", it is necessary to strengthen the empowerment of the digital economy, and cultivate new driving force of high-quality economic development in Henan Province through the empowerment of the digital economy. However, in the current process of Henan Province using the digital economy to cultivate new driving force of high-quality economic development, there has been a problem that the foundation of the digital economy is lagging, so that the expected empowerment value of the digital economy cannot have exerted, and it is difficult to cultivate the economy for Henan Province. New driving force for high-quality development, Henan Province's use of digital economy to cultivate high-quality economic development is lagging behind, mainly as follows. Henan Province's communication pipeline network infrastructure development is lagging, Henan Province's 5G wireless base stations and relay equipment are relatively small, Henan Province's computer rooms at all levels and related supporting facilities Insufficient construction of facilities. The 5G network base station link the another wireless communication devices to the central hub. An architecture of the $5 \mathrm{G}$ base-station consists of several kinds of equipment's to convert RF antenna signals into BUU cabinets by using $5 \mathrm{G}$ base station power amplifier.

\subsubsection{Failure to make full use of the digital economy to cultivate leading companies that promote high-quality economic development}

For Henan Province to achieve high-quality economic development, it needs a group of leading companies as support, just as Zhejiang has cultivated Alibaba, Geely Automobile Group, and Guangdong has cultivated companies such as Tencent, Huawei, and Ping An. At present, the number of leading enterprises in Henan Province in the field of traditional industries is small and most of them are enterprises in the agricultural field, which makes it difficult to form a high-quality driving effect on the economic development of Henan Province. In the context of the "double circulation", the eastern provinces have used the 
digital economy to cultivate leading enterprises in the region. In the face of the abovementioned reality, Henan Province has not made full use of the digital economy, cultivated, and promoted the economy with fewer leading enterprises. Leading enterprises with highquality development are not conducive to the improvement of the quality and speed of the province's economic development. Henan Province has failed to make full use of the digital economy to cultivate leading enterprises that promote high-quality economic development. The specific manifestations are as follows. Henan Province has failed to make full use of the digital economy to cultivate leading Internet platform-type enterprises. Henan Province has failed to make full use of the digital economy to cultivate modern Leading enterprises in the service industry. Henan Province has failed to make full use of the digital economy to promote high-quality growth of enterprises in traditional industries.

\subsubsection{The government has not fully adapted to the needs of the digital economy in cultivating new driving force of high-quality economic development}

Although the economic foundation determines the superstructure, the superstructure has an important influence on the development of the economy. In a certain period, it will even influence the development trend and mode of the economy. Under the background of the "double circulation", Henan Province must cultivate New driving force for high-quality economic growth through the empowerment of the digital economy, and it is inseparable from government support. Whether the local government of Henan Province can cultivate new drivers of high-quality economic development based on the needs of the digital economy. Local governments' implementation of specific functions and adjustments in organizational structure directly affect the empowerment value of the digital economy. Therefore, the demand for high-quality economic development affects whether the high-quality economic development can have achieved smoothly. At present, the Henan Provincial Government pays more attention to the specific implementation measures and effects of how the digital economy is empowered and the digital economy cultivates new driving force of high-quality economic development, but lacks attention to the implementation of deeper government functions and the adjustment of organizational structure. As a result, the digital economy has led to the phenomenon that the performance of government functions and the adjustment of organizational structure lag behind the needs of practical development in the cultivation of New driving force for high-quality economic development, and the incompatibility of the latter as a superstructure will directly restrict the value of the digital economy.

\subsubsection{Enterprises lack talents who can use the digital economy to promote their own innovation and high-quality development}

Under the background of the "double circulation", Henan Province should use the digital economy to cultivate New driving force for high-quality economic development. The ultimate goal lies in whether enterprises can make full use of the digital economy to promote their own innovation and high-quality development, to seize the "double circulation". From the perspective of enterprises, the key to using the digital economy to promote their own innovation and high-quality development lies in the support of talents. Therefore, the quality of corporate talents will directly affect the cost and effect of companies by the digital economy, which promotes their own innovation and high-quality development. However, in practice, there are a large number of enterprises in Henan Province, which lack talents and can use the digital economy to promote their own innovation and high-quality development, which affects the high-quality development of enterprises. The specific manifestations 
are: the lack of leadership talents with "soul" influence within the company, and the lack of specific executive talents with the ability to use the digital economy.

\subsection{Factors for the dilemma of Henan Province's use of digital economy to cultivate new driving force of high-quality economic development under the background of "double circulation"}

\subsubsection{Failure to understand the dual nature of production and consumption of digital infrastructure construction under the background of "double circulation"}

The "double circulation" strategy proposed by the central government takes the expansion of international and domestic cycles as an important measure for China's economic development in the new era and new environment. Among them, expanding domestic cycles is the key. In this context, Henan Province needs to further strengthen its internal production and consumption system in order to seize the policy opportunity of the "double circulation". Among them, the improvement of relevant basic implementation at the level of the digital economy is both a productive input and a special type of "consumption", but in the end both can promote the international and domestic cycles, especially the domestic cycle. However, at present, Henan Province still has certain deficiencies at the cognitive level, and does not have a deep understanding of the duality of production and consumption of digital infrastructure construction under the background of "double circulation".

\subsubsection{Ignoring the status of leading companies in the cultivation of new driving force of high-quality economic development}

Henan Province uses the digital economy to cultivate new driving force for high-quality economic development in Henan Province. Under the background of relatively limited regional resource capacity, Henan Province should grasp the main contradictions and solve the main contradictions first, to promote the settlement of the secondary contradictions by solving the main contradictions. Among them, the leading enterprises are the "pull the ox by the nose (grasp the key link)" that drives the high-quality economic development of Henan Province. They are the main contradiction of cultivating the high-quality economic development of Henan Province with the help of digital economy, and it needs to solve first. For example, the reason why Hangzhou can achieve high-quality economic development based on the Internet industry has closely related to the cultivation of leading companies such as Alibaba Group. However, relevant government departments and enterprises in Henan Province have neglected to train leading enterprises, especially the cultivation of leading enterprises based on the Internet-based digital economy, thus making the region unable to seize the "pull the ox by the nose (grasp the key link)" in the New driving force of high-quality economic development ". As the relevant government departments and enterprises ignore the "pull the ox by the nose (grasp the key link)" status of leading companies, the training of leading companies in the field of Internet digital economy and the training of leading companies in traditional fields based on the digital economy cannot get comprehensive policies and necessary resource support. It is difficult for the training of leading enterprises to achieve the expected goals, and it is difficult for leading enterprises to drive high-quality economic development in Henan Province. 


\subsubsection{Insufficient enthusiasm and resistance to the transformation of government functions and organizational structure adjustment}

According to the previous analysis, Henan Province uses the digital economy to cultivate new driving force of high-quality economic development under the background of the "double circulation". The transformation of government functions and the lagging adjustment of organizational structure are also one of the outstanding problems. The reason for the above problems is the lack of enthusiasm and resistance in the transformation of government functions and the adjustment of organizational structure.

1. The enthusiasm of local government function transformation and organizational structure adjustment is insufficient. The transformation of functions and the adjustment of organizational structure from the government level is a very complex behavior, involving the coordination and handling of multiple interests, and there may even be some negative events due to the transformation of functions and the adjustment of organizational structure. At the same time, from the perspective of the government, especially the local government (district and county governments), it only needs to maintain the steady economic development to meet the basic governance requirements. There is no mandatory requirement for whether to use the digital economy to cultivate new driving force for high-quality economic development.. Therefore, in practice, although local governments support the use of digital economy to cultivate new driving force of high-quality economic development in terms of slogans and certain policies, there is a clear lag in functional transformation and organizational structure adjustment.

2. There is a certain resistance to the transformation of local government functions and the adjustment of organizational structure. If based on the purpose of using the digital economy to cultivate new drivers of high-quality economic development, local governments will promote the transformation of government functions and promote the adjustment of organizational structures. This will inevitably pose a challenge to the original interest structure, and even lead to the loss or weakening of the interests of certain stakes.

\subsubsection{The introduction and training system of high-quality professionals in the field of digital economy is lacking}

Enterprises rely on the digital economy to promote their own innovation and high-quality development. It is inseparable from the contribution of every specific employee. Only employees in each position can achieve their expected development goals when they play their respective position values. However, in practice, some enterprises in Henan Province still lack high-quality professionals for the use of digital economy, which affects the innovation and high-quality development of enterprises. The direct cause of the above problems is that some enterprises have not established the introduction and training of high-quality professionals. 


\subsection{Countermeasures for Henan Province to use the digital economy to cultivate new driving force of high-quality economic development under the background of "double circulation"}

\subsubsection{Layout of Henan Province's digital infrastructure construction to build a solid foundation for high-quality economic development}

At present, the digital economy has entered the era of "full industry chain" competition. The core competitiveness of the industry has shifted from the competition of a single technology, a single product and a single enterprise to the competition of platforms and ecosystems. The five major systems, including the layer and application layer, are working hard to promote the coordinated development of hardware, software, and services, forming a digital economy ecosystem that has international competitive advantages and is safe and controllable. Accelerate the construction of intelligent information infrastructure that integrates perception, transmission, storage, computing, and processing, enhance the intelligence level of traditional infrastructure, strengthen data security and privacy protection, and form an intelligent economy, intelligent society and national defense construction needs Infrastructure system.

\subsubsection{Cultivating a group of leading companies at the high end of the industrial value chain with consumption upgrading as the engine}

1. Cultivating leading Internet platform enterprises with consumption upgrade as the engine Under the background of "double circulation", Henan Province uses the digital economy to cultivate New driving force for high-quality economic development. The double or dual circulation strategy is termed as economic development pattern. It takes the support of domestic development and international development. It mainly used to improve the china's export oriented development strategy rapidly. One of the key points is to cultivate a group of leading companies at the high end of the industrial value chain, thereby improving the quality of Henan's corporate economic development. Among them, combined with the characteristics of the times and the status of Henan Province in the development of Internet platform enterprises, Henan Province needs to use consumption upgrades as the engine to cultivate leading Internet platform enterprises.

2. Cultivating leading enterprises in the modern service industry with consumption upgrading as the engine

In the process of economic development in Henan Province, the relatively lagging development of the service industry is a relatively prominent problem, and the development of the service industry is particularly important in the process of high-quality development of the modern economy. With the consumption upgrade of consumers under the background of "double circulation", the development of the service industry in Henan Province has ushered in historical opportunities and unprecedented challenges. In this context, cultivating leading enterprises in the modern service industry with consumption upgrading as the engine is an alternative way for Henan Province to seize opportunities, respond to challenges, and achieve high-quality development of the service economy.

3. To build a number of leading companies in traditional industries with consumption upgrade as the engine

At present, traditional industries still account for a large proportion of the economic structure of Henan Province, and the dominant position of traditional industries cannot have shaken in the short term, whether in terms of GDP contribution or employment. At the same 
time, the current traditional industries in Henan Province are mostly in the middle of the "smiling curve", that is, in the low value-added area of the industrial chain. In the face of the above-mentioned situation, in order to promote the high-quality development of Henan's traditional industrial economy, it is necessary to make full use of the digital economy to push enterprises in traditional industries to move to both sides of the "smiling curve." Engine has built several leading companies in traditional industries, to improve the overall development quality of traditional industries in Henan Province through the drive of leading companies.

\subsubsection{Improve the government support system and build a support system for high-quality economic development in Henan Province}

According to the previous analysis, it can be seen that under the background of "double circulation", Henan Province still has the problem of misalignment between the performance of government functions and actual needs with the help of digital economy to cultivate New driving force for the high-quality development of the province's economy. To this end, Henan Province must build a service-oriented government under the digital economy to strengthen the ability to support high-quality economic development. Specifically, the first is to promote the transformation of the government from a management-oriented government to a service-oriented government. The construction of a service-oriented government has generally recognized by the society, and the central government has repeatedly proposed to promote the construction of a service-oriented government. However, in practice, the construction of service-oriented government in the localities has not been able to achieve the expected results. The "official rank standard" idea is still "rampant" in some local governments, and some local governments have not been able to actively transform from the role of manager to the role of service. Therefore, in order to improve the ability to use the digital economy and cultivate higher-quality new driving force for the economic development of Henan Province, Henan Province must promote the transformation of the government from a management-oriented government to a service-oriented government, and strengthen the assessment of the service level of government departments. Urge government staff to change their status as service providers. At the same time, build the necessary reward and punishment mechanism to guide, encourage and punish the transformation of government functions, accelerate the transformation of government functions to a service-oriented direction, and strengthen the ability to support high-quality economic development. The second is to guide government staff to change their work thinking and strengthen their position as a "servant". Third, in-depth analysis of the new driving force of high-quality economic development in Henan Province under the digital economy, specific needs for the performance of government functions, and advancement with the times from the perspective of development, promote the continuous and dynamic adjustment of the performance of government functions.

\subsubsection{Build a systematic talent training and application system}

It is also very important to build a systematic talent training system in the process of building a high-quality digital economy talent team for enterprises in Henan Province. Organization with wide integration and consistent management approach is called as systematic talent management approach. If the system are more integrated means the satisfaction rate of the client is improved automatically. But the systematic talent management approach deals with only minimum number of people to fulfil their needs rapidly. To this end, enterprises in Henan Province specifically need to make improvements in the following aspects. 
1. Strengthen personnel training and evaluation. Whether it is externally recruited talents or internal talents, to improve their competence in the use of digital economy, it is necessary to strengthen talent training. In the process of implementing talent training, enterprises in Henan Province should not have limited to traditional non-scheduled lectures or informal exchange-style training within the team, but should organize specialized and high-quality training activities on a regular basis.

2. Under the background of the coordination of voluntary selection and obedience to the company's arrangements, different talents have arranged to suitable positions according to their talents and specialties, to realize the matching of personnel and positions to strengthen the implementation measures for the digital economy in Henan enterprises. Guarantee strength.

3. Assessment and withdrawal (elimination). In order to motivate employees and impose reasonable pressure on employees, it is necessary for enterprises in Henan Province to introduce a performance appraisal mechanism and an exit (elimination) mechanism. In this way, it forms a normative guide to the behavior of employees, so that they can participate more actively in the job.

Acknowledgements The work is supported by 2021 Henan Province KeyR\&D and Promotion Special Project 702(soft scientific research), Project Number: 212400410078, and 2020 Zhengzhou City Soft Science Research 703 Plan Project, Project Number: 2020RKXF0099, and Final research findings of Henan Province Philosophy and Social Science Planning Project, Project Number: 2020BJJ058.

\section{References}

Abdel-Basset, M., Manogaran, G., Gamal, A., \& Smarandache, F. (2018). A hybrid approach of neutrosophic sets and DEMATEL method for developing supplier selection criteria. Design Automation for Embedded Systems, 22(3), 257-278. https://doi.org/10.1007/s10617-018-9203-6

Alvarez, J. M., \& Crespo, R. G. (2013). Design of a triple helix strategy for developing nations based on E-Government and entrepreneurship. Advances in Electronic Government, Digital Divide, and Regional Development Digital Public Administration and E-Government in Developing Nations, https://doi. org/10.4018/978-1-4666-3691-0.ch007

Balusamy, B., Jha, P., Arasi, T., \& Velu, M. (2019). Predictive analysis for digital marketing using big data. Web Services,. https://doi.org/10.4018/978-1-5225-7501-6.ch041

Cao, Z. (2018). Research on the new manufacturing model that promotes the high-quality development of China's industry under the background of digital economy. Theoretical Discussion, 2, 99-104.

Ding, Z. (2020). Research on the mechanism of digital economy driving high-quality economic development: A theoretical analysis framework. Modern Economic Research, 1, 85-92.

Fan, Y., \& Xu, H. (2020). Financial assistance to the high-quality development of the digital economy: Core mechanism and experience enlightenment. Reform, 8, 83-91.

Grigorescu, A., Pelinescu, E., Ion, A. E., et al. (2021). Human capital in digital economy: An empirical analysis of Central and Eastern European Countries from the European Union. Sustainability, 13(4), 2020-2022.

Guo, H., \& Lian, Y. (2020). Digital economy and the cultivation of new driving force of China's future economy. Journal of Northwest University (philosophy and Social Sciences Edition), 50(1), 65-72.

Han, C., \& Dong, F. (2020). Research on the cultivation of digital new driving force of economic development in Shandong Province. Journal of Qingdao Agricultural University (social Science Edition), 32(3), 47-50.

Jia, H., Guo, Y., Chu, H., \& Ye, G. (2020). Empirical analysis of digital economy driving economic development in the post-epidemic era. Industrial Technology Economy, 39(11), 138-144.

Jing, W., \& Sun, B. (2019). Digital economy promotes high-quality economic development: A theoretical analysis framework. Economist, 2, 66-73.

Li, X., Lu, X., Xue, F., \& Tao, H. (2020). Residents' emerging consumption cultivation strategies under the background of "double circulation"___A case study of Jiangxi. Enterprise Economics, 39(11), 134-141.

Liu, S. (2019). Targeted path and policy supply for the high-quality development of China's digital economy. Economist, 6, 52-61. 
Nguyen, N., Leu, M.C., Liu, X. F. (2017). Real-time communication for manufacturing cyber-physical systems. In 2017 IEEE 16th international symposium on network computing and applications (NCA) (pp. 1-4) Cambridge. https://doi.org/10.1109/NCA.2017.8171361

Raza, M., et al. (2020). A digital twin framework for industry 4.0 enabling next-gen manufacturing. In: 2020 9th international conference on industrial technology and management (ICITM). https://doi.org/10.1109/ icitm48982.2020.9080395

Ren, B. (2020). The logic, mechanism and path of digital economy leading high-quality development. Journal of xi' an University of Finance and Economics, 33(2), 5-9.

Shen, K., \& Zhao, Q. (2020). Promote high-quality economic development during the "14th Five-Year Plan" period with a new dual-cycle development pattern. Economic Aspects, 10, $28-35$.

Sheng, L. (2020). Digital economy leads the high-quality development of industry: dynamic mechanism, internal logic and implementation path. Price Theory and Practice, 2020(2), 13-17+34.

Shi, B. (2020). The mechanism and path of digital economy to promote the high-quality development of urban economy. Journal of xi'an University of Finance and Economics, 33(2), 10-14.

Sturiale, L., \& Scuderi, A. (2016). The digital economy: New e-business strategies for food Italian system. International Journal of Electronic Marketing and Retailing, 7(4), 287-288.

$\mathrm{Su}, \mathrm{M} .$, \& Xia, J. (2020). The mechanism and path of the digital economy empowering the double circulation. Open Herald, 6, 71-75.

Wang, Y. (2020). Economic development under the new pattern of "double circulation." China Finance, 17, $21-23$.

Wang, K., Wu, G., \& Zhang, G. (2020). Has the development of digital economy improved production efficiency? Economist, 10, 24-34.

Zhang, W. (2019). Vigorously developing the digital economy is the only way for high-quality development. Red Flag Manuscript, 387(3), 27-29.

Wen, J., Deng, P., \& Zhang, Q. (2020). How does digital economy innovation reshape the path of high-quality development. Journal of Humanities, 11, 98-108.

Xiao, G., \& Zhang, L. (2019). Research on the impact of digital economy development on China's regional total factor productivity. Journal of Hefei University of Technology (social Science Edition), 33(5), 6-12.

Yang, H. (2020). Research on the growth efficiency of digital economy and the high-quality development of China's economy. Research on Socialism with Chinese Characteristics, 3, 21-32.

Zhang, M. (2020). How to systematically and comprehensively understand the new development pattern of "double circulation"? Journal of Liaoning University (philosophy and Social Sciences Edition), 48(4), $1-8+2$.

Zhang, H., Liu, Z., \& Wang, S. (2019). Analysis of China's high-quality economic development path under the background of digital economy. Business Economics Research, 23, 183-186.

Zhu, H., \& Wang, C. (2020). Digital economy leads the high-quality development of industries: Theory, mechanism and path. Finance Theory and Practice, 41(5), 5-13.

Publisher's Note Springer Nature remains neutral with regard to jurisdictional claims in published maps and institutional affiliations. 